\title{
Neutrophil activation in septic acute kidney injury : A post hoc analysis of the FINNAKI study
}

\section{Törnblom, Sanna}

2019-11

Törnblom , S , Nisula , S , Vaara , S T, Poukkanen, M , Andersson , S , Pettilä , V \& Pesonen, E 2019 , ' Neutrophil activation in septic acute kidney injury : A post hoc analysis of the FINNAKI study ' , Acta Anaesthesiologica Scandinavica, vol. 63 , no. 10 , pp. 1390-1397 . https://doi.org/10.1111/aas.13451

http://hdl.handle.net/10138/312955

https://doi.org/10.1111/aas.13451

acceptedVersion

Downloaded from Helda, University of Helsinki institutional repository.

This is an electronic reprint of the original article.

This reprint may differ from the original in pagination and typographic detail.

Please cite the original version. 
DR SANNA TÖRNBLOM (Orcid ID : 0000-0003-0534-9204)

PROFESSOR VILLE PETTILÄ (Orcid ID : 0000-0002-3921-4423)

Article type : Clinical investigation

\title{
Neutrophil activation in septic acute kidney injury: A post-hoc analysis of the FINNAKI study
}

\author{
Sanna Törnblom ${ }^{1 *}$, Sara Nisula ${ }^{1}$, Suvi T. Vaara ${ }^{1}$, Meri Poukkanen $^{2}$, Sture Andersson $^{3}$, Ville \\ Pettilä ${ }^{1}$, Eero Pesonen ${ }^{4}$
}

${ }^{1}$ Department of Anaesthesiology, Intensive Care and Pain Medicine, Division of Intensive Care Medicine, University of Helsinki and Helsinki University Hospital, Helsinki, Finland

${ }^{2}$ Department of Anaesthesia and Intensive Care Medicine, Lapland Central Hospital, Rovaniemi, Finland

${ }^{3}$ Department of Paediatrics, Children's Hospital, University of Helsinki and Helsinki University Hospital, Helsinki, Finland

${ }^{4}$ Department of Anaesthesiology, Intensive Care and Pain Medicine, Division of Anaesthesiology, University of Helsinki and Helsinki University Hospital, Helsinki, Finland

Short title: Activin A, IL-8 and MPO in septic AKI

This article has been accepted for publication and undergone full peer review but has not been through the copyediting, typesetting, pagination and proofreading process, which may lead to differences between this version and the Version of Record. Please cite this article as doi: 10.1111/aas.13451

This article is protected by copyright. All rights reserved. 
*Correspondence: Sanna Törnblom,

Department of Anaesthesiology, Intensive Care and Pain Medicine, Division of Intensive Care Medicine, P.O. box 340, Helsinki, Finland, FI-00029 HUS, tel. +358 504279130

Email: sanna.tornblom@ @us.fi

\section{Abstract}

Background: Inflammation, reflected by high plasma interleukin- 6 concentration, is associated with acute kidney injury (AKI) in septic patients. Neutrophil activation has pathophysiological significance in experimental septic AKI. We hypothesised that neutrophil activation is associated with AKI in critically ill sepsis patients.

Methods: We measured plasma $(n=182)$ and urine $(n=118)$ activin A (a rapidly released cytosolic neutrophil protein), interleukin-8 (a chemotactic factor for neutrophils), myeloperoxidase (a neutrophil biomarker released in tissues), and interleukin-6 on intensive care unit admission (plasma and urine) and 24 hours later (plasma) in sepsis patients manifesting their first organ dysfunction between 24 hours preceding admission and the second calendar day in intensive care unit. AKI was defined by the Kidney Disease: Improving Global Outcomes criteria.

Results: Plasma admission interleukin-8 [240 (60-971) vs. 50 (19-164) pg/ml, p<0.001] and activin A [845 (554-1895) vs. 469 (285-862) pg/ml, p<0.001] were but myeloperoxidase [169 (111-300) vs. 144 (88-215) $\mathrm{ng} / \mathrm{ml}, \mathrm{p}=0.056]$ was not higher among patients with AKI compared with those without. Urine admission interleukin-8 [50.4 (19.8-145.3) vs. 9.5 (2.728.7) $\mathrm{ng} / \mathrm{ml}, \mathrm{p}<0.001]$ and myeloperoxidase [7.7 (1.5-12.6) vs. $1.9(0.4-6.9) \mathrm{ng} / \mathrm{ml}, \mathrm{p}<0.001]$

This article is protected by copyright. All rights reserved. 
were but activin A [9.7 (1.4-42.6) vs. $4.0(0.0-33.0) \mathrm{ng} / \mathrm{ml}, \mathrm{p}=0.064]$ was not higher in AKI than non-AKI patients. Urine myeloperoxidase correlated with urine interleukin-8 $(R=0.627$, $p<0.001)$ but not with plasma myeloperoxidase $(R=0.131, p=0.158)$.

Conclusion: Interleukin-8 in plasma and urine was associated with septic AKI. Elevated plasma activin A indicates intravascular neutrophil activation in septic AKI. Concomitant plasma and urine myeloperoxidase measurements suggest neutrophil accumulation into injured kidneys.

\section{Editorial Comment}

Acute kidney injury in sepsis is common, however the pathophysiology behind it is still unclear. This prospective observational study reveals that neutrophil activation in plasma can be transferred to excretion of neutrophil activation products in urine, and this is linked to kidney injury, at least in sepsis.

\section{Introduction}

Acute kidney injury (AKI) is a common syndrome with an increasing incidence among hospitalized patients. ${ }^{1}$ In a recent prospective cohort of more than 15,000 patients, ${ }^{2}$ AKI was diagnosed in $32 \%$ of intensive care patients according to the Kidney Disease: Improving Global Outcomes (KDIGO) criteria. ${ }^{3}$ Sepsis is the most common contributing factor to AKI in critically ill patients, but the pathophysiological mechanisms of septic AKI are still insufficiently understood. ${ }^{4}$ Growing evidence supports an inflammatory etiology of AKI instead of hypoperfusion related mechanisms. ${ }^{5}$ Recently, a unified theory of sepsis-induced AKI has been proposed. ${ }^{6}$ According to the theory, inflammation causes diffuse microcirculatory flow abnormalities and cell bioenergetic adaptive responses leading to the 
clinical manifestation of AKI. As a reflection of a pro-inflammatory reaction, high plasma interleukin-6 (IL-6) concentration has been linked to septic AKI. ${ }^{7,8}$ Experimental evidence supports neutrophil activation in septic AKI. In AKI induced either by endotoxin or by cecal ligation and puncture, neutrophils have been demonstrated to infiltrate the kidney. Vice versa, neutrophil depletion and interventions reducing renal neutrophil accumulation protect from AKI. ${ }^{9-14}$ Neutrophil infiltration correlates with the degree of deterioration of renal function. ${ }^{10}$

Activin $A$ is a member of transforming growth factor- $\beta$ superfamily. ${ }^{15}$ It is a $25 \mathrm{kD}$ homodimer with a disulfide bridge. Along its numerous other functions, activin A possesses both proand anti-inflammatory properties in innate immunity. In experimental endotoxemia, serum activin A concentration rises within one hour after lipopolysaccharide (LPS) challenge simultaneously with tumor necrosis factor- $\alpha$ and earlier than interleukins $1 \beta$ and $6 .{ }^{16-18}$ Neutrophils, in which preformed activin A is located in the cytosol, are the main source of rapidly released activin $A .{ }^{15,19-21}$ Neutrophils are not only the source but also the target of activin $A$, because activin $A$ enhances neutrophilic phagocytic function and oxidative burst. ${ }^{22}$ In critically ill sepsis patients, and in patients with acute respiratory failure, increased serum activin A concentration is associated with disease severity. ${ }^{23-25}$ Interleukin-8 (IL-8) is a chemokine involved in neutrophil activation during inflammation. It is a strong chemotactic factor for neutrophils and induces their priming activity in septic patients. ${ }^{26-28}$ Neutrophilderived oxygen free radicals and proteases have pathophysiological significance in endotoxin-induced septic AKI. ${ }^{29}$ Renal neutrophil accumulation is accompanied with increased renal myeloperoxidase (MPO) activity, indicating that sequestered neutrophils release their cytotoxic contents in the renal interstitium ${ }^{12-13}$.

This article is protected by copyright. All rights reserved. 
The aim of this study was to gain knowledge of the proposed inflammatory mechanisms, especially neutrophil activation, underlying septic AKI. We hypothesized that activin A as a readily released cytosolic protein of neutrophils, IL-8 as a strong endogenous chemotactic factor for neutrophils, and MPO as a biomarker of neutrophil azurophilic granules would be associated with sepsis-induced AKI among critically ill adult patients.

\section{Methods}

Reporting is in accordance with the STROBE statement on reporting observational cohort studies.

\section{Patients}

We studied a subgroup of adult intensive care unit (ICU) patients with severe sepsis from the prospective FINNAKI (FINNish Acute Kidney Injury) study, which included all eligible ICU patients from 17 Finnish ICUs between September 2011 and February 2012. The inclusion and exclusion criteria for this study are outlined in the original report. ${ }^{30}$ The FINNAKI study patients were screened for severe sepsis, defined by the American College of Chest Physicians/Society of Critical Care Medicine criteria, ${ }^{31}$ on admission and throughout the first five days of intensive care. Plasma samples were collected from the whole FINNAKI study period. Centrifuged urine samples were available from the last three months of the study. To detect early events of inflammation, we evaluated 237 consecutive patients who fulfilled the criteria for severe sepsis within 24 hours preceding ICU admission, during the admission day (D0), or the first complete calendar day (D1) in the ICU. To ensure the availability of urine samples in addition to plasma samples, the consecutive collection of the patients was started from the end of the FINNAKI study period backwards. We excluded patients with chronic kidney disease (glomerular filtration rate less than $60 \mathrm{ml} / \mathrm{min} / 1.73 \mathrm{~m} 2$ ) and those without both admission and $24 \mathrm{~h}$ plasma samples available (Figure 1). The Ethics 
Committee of the Department of Surgery in Helsinki University Hospital gave a nationwide approval for the FINNAKI study. To avoid delay in taking the first sample, the Ethics Committee granted a deferred consent policy. This was later confirmed by a written consent of the patient or his/her proxy.

\section{Blood and urine samples}

Blood samples were drawn from the peripheral arterial cannula into ethylenediaminetetraacetic acid tubes at the time of admission to the ICU ("O hours") and 24 hours later ("24 hours"). The urine samples were collected at the time of admission to the ICU ("0 hours"). Plasma and urine samples were centrifuged and aliquoted immediately after ICU admission or at 2 hours at the latest, and stored at $-80^{\circ} \mathrm{C}$ until assayed. Including aliquoting and analyses, the plasma samples were thawed maximum of three times and urine samples maximum of two times. We used commercial enzyme-linked immunosorbent assay (ELISA) kits for activin A (Quantikine, R\&D Systems, Abingdon, UK; detection limit 4 pg/ml), IL-8 (Cymax, Abfrontier, Seoul, South-Korea; detection limit 0.3 pg/ml), IL-6 (DiaClone, Besancon, France; detection limit 2 pg/ml), and MPO (BioLegend Inc., San Diego, CA, USA; detection limit $28 \mathrm{pg} / \mathrm{ml}$ ) analyses. All plasma and urine samples were assayed in duplicate according to the manufacturer's instructions.

\section{Clinical data}

The clinical data were prospectively collected using a standardized case report form (CRF) filled daily by the attending clinician. The chronic and present health status, criteria for severe sepsis and septic shock, sepsis-related organ dysfunction, and information on administered renal replacement therapy (RRT) were recorded. The CRF data also contained the lowest and/or highest values (indicated as "minimum" or "maximum" in the results section) of predetermined laboratory tests, i.e. leukocyte count, C-reactive protein (CRP), 
platelet count, international normalised ratio (INR), $\mathrm{pH}$, base excess, and plasma lactate for the period of 24 hours prior to ICU admission, including the time of ICU admission. Physiologic data including Acute Physiology and Chronic Health Evaluation II (APACHE II), Simplified Acute Physiology Score II (SAPS II), urinary output, and Sequential Organ Failure Assessment (SOFA) scores of the first five days of ICU stay were collected from the database of the Finnish Intensive Care Consortium maintained by Tieto Ltd, Helsinki, Finland as described in the original report. ${ }^{30}$

AKI was defined and classified into three stages, according to the KDIGO criteria, by changes in serum creatinine and urine output. ${ }^{3}$ Urine output was measured hourly and serum creatinine daily. The last available serum creatinine value from the preceding year up to one week before admission to intensive care was used as the baseline value for each patient. If not available, the baseline creatinine value was estimated using the Modification of Diet in Renal Disease equation assuming a glomerular filtration rate of $75 \mathrm{ml} / \mathrm{min} / 1.73 \mathrm{~m}^{2}{ }^{32}$ We screened for the presence of AKI throughout the first five days of ICU stay, and the highest stage was chosen for the final KDIGO stage of each study patient.

\section{Statistical analysis}

The study patients were staged a priori according to the KDIGO classification. Because activin A, IL-8, IL-6, and MPO plasma concentrations were not normally distributed, we used non-parametric tests. To estimate sample size for the present study, we utilized previous clinical data of septic AKI reporting approximately 3-fold plasma IL-6 concentrations in patients with $\mathrm{AKI}$ compared with those without $\mathrm{AKI}^{8}$ and unpublished plasma IL-6 concentration data from a pilot study of 32 severe sepsis patients from our laboratory showing a 2-fold increase. As a result, when using the distribution of our pilot study and taking into account the non-normal distribution of plasma IL-6, a minimum of 60

This article is protected by copyright. All rights reserved. 
patients/group would have been needed to achieve $80 \%$ power in detecting a 2.5 -fold increase in plasma IL-6 concentration between AKI and non-AKI patients. We decided to enlarge our cohort to approximately 90 patients per group for analyses of plasma activin A, IL-8, and MPO without previous data available for power estimations.

We conducted logistic regression analysis to test if comorbidities or disease severity contributed to $\mathrm{AKI}$, entering all covariates at the same time, not stepwise. To compare groups, we used chi-square or Fisher's exact test for categorical variables and MannWhitney $U$ test for continuous variables. For comparisons between KDIGO stages 1-3, we conducted Kruskal-Wallis test and took multiple comparisons into account by using pairwise comparison as a post-hoc test. We illustrated diagnostic accuracy with areas under the curve of the receiver operating characteristic (AUCs). Recently, a definition of "severe" AKI comprising of KDIGO stages 2 and 3 has been applied in biomarker studies. ${ }^{33,34}$ Consequently, we calculated AUCs for both the original KDIGO AKI definition (i.e. stages 1-3 vs. stage 0) and KDIGO criterion of a "severe" AKI (i.e. stages 2-3 vs. stages 0-1). We applied Bonferroni correction when comparing the two time points in patients with KDIGO stages $0-3$, and a p value $<0.0125$ was considered significant. Otherwise, a $p$ value $<0.05$ was considered significant. The data are expressed as counts and percentages or as medians with interquartile ranges (IQR), and AUCs are given with 95\% confidence intervals. Statistical analyses were conducted using SPSS 22 software (SPSS Inc., Chicago, IL, USA).

\section{Results}

\section{Patients}

Figure 1 presents the study flow chart. We included 182 patients, of whom 97 (53\%) fulfilled severe sepsis criteria on admission and 85 (47\%) during the day of ICU admission (D0) or the following day (D1), illustrated in Figure S1 in the supplements. The patient

This article is protected by copyright. All rights reserved. 
characteristics and the clinical outcomes of all 182 patients are presented in Table 1. AKI was diagnosed in 92 of $182(51 \%)$ patients (Figure 1, Table 1), of whom 50 (54\%) were diagnosed with AKI on ICU admission day (D0), 35 (38\%) on day 1 and 7 (7.6\%) on days 2-

4. Of 92 patients with AKI, 37 (40\%) had KDIGO stage 1, 19 (21\%) stage 2 and $36(39 \%)$ stage 3 AKI. The time of fulfilling KDIGO AKI criteria in relation to ICU admission is shown in Figure S2. 26 (14\%) patients commenced RRT in the ICU. A history of hypertension and septic shock were more frequent among patients with AKI than in those without. AKI patients had higher maximum SOFA score even if renal points were subtracted (Table 1). Of age, gender, co-morbidities, admission type and disease severity variables in table 1 , only diabetes, systolic heart failure and maximum SOFA score without renal points were associated with AKI.

\section{Plasma measurements}

We analysed IL-6 and MPO from both $0 \mathrm{~h}$ and $24 \mathrm{~h}$ plasma samples of all 182 patients. IL-8 was analysed of 180 patients and activin $A$ of 179 patients due to insufficient samples from a few study patients. The measured laboratory parameters in plasma at 0 and 24 hours according to the presence or absence of AKI are presented in Table 2. Activin A, IL-8, and IL-6 were higher in AKI than in non-AKI patients at both time points ( $p \leq 0.001$ for all). MPO was higher in patients with AKI than in those without at 24 hours but not at 0 hours. Leukocyte count and CRP value did not differ between AKI and non-AKI patients.

Activin A, IL-8, IL-6, and MPO at both time points ( $0 \mathrm{~h}$ and $24 \mathrm{~h}$ ) according to KDIGO stage are presented in Figure 2. Activin A concentration was higher in patients with KDIGO stage 3 than stage 1 at both time points. IL-8 and MPO levels were higher in KDIGO stage 3 than in stage 1 at 24 hours but not at 0 hours. AUCs for AKI were better for plasma activin A [0.706 $(0.630-0.782)]$ and IL-8 $[0.710(0.634-0.785)]$ than for IL-6 [0.644 (0.562-0.725)] or MPO

This article is protected by copyright. All rights reserved. 
[0.566 (0.482-0.650)], and did not improve with the outcome "severe" (=KDIGO 2-3) AKI (Table S1).

\section{Urine measurements}

Urine samples on ICU admission were available in 118 patients. The correlations between the plasma and urine concentrations of activin A, IL-8 and IL-6 were weak $(R=0.335-0.415$, all $p<0.001)$. Urine MPO did not correlate with plasma MPO $(R=0.131, p=0.158)$. Urine MPO correlated with urine IL-8 $(\mathrm{R}=0.627, \mathrm{p}<0.001$, Figure $\mathrm{S} 3$ of the supplementary material). Urine IL-8, IL-6 and MPO were higher in AKI than in non-AKI patients $(p<0.001$ for all, Table 2), but there was no difference in activin A levels between the groups (Table 2). Urine activin A, IL-8, IL-6, and MPO at 0 hours according to KDIGO stage are presented in Figure 3. IL-8 levels were higher in KDIGO stage 3 than in stage 1. In urine, IL-8 had the highest AUCs [0.765 (0.677-0.852) for AKI and $0.827(0.749-0.905)$ for "severe" AKI], followed by MPO, IL6, and activin A (Table S1).

\section{Discussion}

In this post-hoc analysis we evaluated the association between AKI and biomarkers indicating neutrophil activation in a cohort of critically ill adult patients with sepsis. We found that activin A and IL-8 in plasma, and MPO and IL-8 in urine were associated with septic AKI.

We found plasma activin A concentrations comparable to previous studies. ${ }^{23}$ Plasma activin A was associated with septic AKI both at 0 and 24 hours. Among AKI patients, activin A differed according to severity of AKI already at 0 hours. Previously, activin A has been observed to correlate with the disease severity and mortality in septic patients. ${ }^{23}$ To our

This article is protected by copyright. All rights reserved. 
knowledge, plasma IL-8 in the evolution of septic AKI has not been previously investigated. Of the studied AKI markers of the present study, IL-8 had the strongest association with septic AKI when measured in plasma or urine on admission. IL-8 levels differed between KDIGO stages of AKI. These data are in line with a previous study on pediatric cardiac surgical patients showing that IL-8 was more strongly associated with AKI than IL-6. ${ }^{36}$

In sepsis, IL-8 primes neutrophils for enhanced production of reactive oxygen species. ${ }^{26}$ Despite this, plasma MPO, a traditional biomarker of neutrophil activation, was only modestly higher in AKI patients than in non-AKI patients at 24 hours after ICU admission, but not on admission. Plasma interleukin concentrations reflect systemic activation of inflammation. Plasma neutrophil biomarker concentrations indicate systemic neutrophil activation in the intravascular space. Activin A, which is located in the neutrophil cytosol, is rapidly released to plasma upon neutrophil activation. ${ }^{15,19-21}$ On the contrary, MPO-containing azurophilic granules show the lowest propensity to degranulate in the intravascular space. ${ }^{37}$ The discriminative performance of MPO (with an AUC of 0.57) was seemingly weaker than that (AUC 0.85 to 0.88 ) previously reported for heparin binding protein (HBP), a granule protein of the neutrophilic secretory vesicles. ${ }^{33,34}$ Secretory vesicles are released upon neutrophil adhesion on the endothelium, i.e. while still in the intravascular space. MPO is mainly released after neutrophil extravasation in the tissues. ${ }^{37}$ Apparently, neutrophil biomarkers in plasma seem to differ substantially in their performance to reflect intravascular neutrophil activation.

Biomarker concentrations in urine are a combined result of their release from the renal parenchyma and the renal excretion of the circulating plasma pool of the biomarker. Comparison of the urinary biomarker concentrations with concomitant plasma concentrations may give some hints of the phenomena occurring in the kidney itself. Such a comparison,

This article is protected by copyright. All rights reserved. 
however, is not straightforward. Proteinuria and oliguria, two attributes of AKI, most likely have a tendency to increase the observed urine concentration of the biomarker. There were modest correlations between the plasma and urine concentrations of activin A, IL-8 and IL-6. Interestingly, urinary MPO did not correlate with plasma MPO. This suggests that plasma MPO is not a major determinant of urinary MPO concentrations. This, in turn, may imply that urine MPO reflects the MPO released in the renal parenchyma. Urine MPO level not only associated with AKI but also correlated with urine IL-8 level. As IL-8 is a strong endogenous chemotactic factor for neutrophils ${ }^{26,27}$ and MPO is released first and foremost in the tissues, ${ }^{37}$ we suggest that renal accumulation of neutrophils may be associated with septic AKI. The present findings are in accordance with previous experimental findings. Increased renal MPO activity accompanied experimental AKI induced by endotoxemia or cecal ligation and puncture. ${ }^{12-13}$

Our study has some limitations. First, because maximum SOFA score without renal points was independently associated with AKI, plasma biomarkers may reflect disease severity in general instead of AKI specifically. This fact, however, does not rule out pathophysiological significance of sequestration of systemically activated neutrophils in the kidney. Second, we evaluated only patients who fulfilled the criteria for severe sepsis close to ICU admission. Considering the rapid kinetics of neutrophil activation, this enabled us to minimise the confounding effect of the disease phase to the results. However, a substantial proportion of patients presented with $\mathrm{AKI}$ already before or during the sampling period. Thus, our findings do not enable calculations of true predictive values of the studied biomarkers regarding developing AKI. Third, the present subgroup of patients was comparable with the larger severe sepsis subgroup of the FINNAKI cohort in all respects except in slightly lower median age [62 (52-72) vs. 65 (55-75) years] and longer length of ICU stay [4.6 (2.7-8.0) vs. 4.0 (1.9-7.3) days]. ${ }^{39}$ By excluding patients without both $0 \mathrm{~h}$ and $24 \mathrm{~h}$ plasma samples available we probably excluded some patients who died during the first 24 hours in the ICU. This

This article is protected by copyright. All rights reserved. 
could explain the longer ICU length of stay in our subgroup. However, the excluded patients did not differ from the included individuals in terms of co-morbidities and disease severity (Table S2 of the supplementary material). Consequently, we believe that the patients of the present study are a representative sample of a larger unselected severe sepsis cohort of adult patients admitted to ICUs nationwide, which increases the generalisability of our results.

\section{Conclusion}

IL-8 was associated with septic AKI both in plasma and urine in critically ill adults. Elevated plasma activin A in patients with AKI suggests an association of intravascular neutrophil activation with septic AKI. Based on concomitant plasma and urine MPO measurements, this may lead to accumulation and activation of neutrophils in the kidneys, and development of AKI.

\section{Acknowledgements}

\section{Funding}

The study has been supported by the Sigrid Juselius Foundation, Päivikki and Sakari Sohlberg

Foundation, and Institutional Grants from the Helsinki University Hospital.

\section{Conflict of interest}

The authors have no conflicts of interest.

This article is protected by copyright. All rights reserved. 


\section{References}

1. Xue JL, Daniels F, Star RA, Kimmel PL, Eggers PW, Molitoris BA, Himmelfarb J, Collins AJ. Incidence and mortality of acute renal failure in Medicare beneficiaries, 1992 to 2001. J Am Soc Nephrol. 2006;17:1135-1142.

2. Srisawat N, Sileanu FE, Murugan R, Bellomod R, Calzavacca P, Cartin-Ceba R, Cruz D, Finn J, Hoste EE, Kashani K, Ronco C, Webb S, Kellum JA; Acute Kidney Injury-6 Study Group. Variation in risk and mortality of acute kidney injury in critically ill patients: a multicenter study. Am J Nephrol. 2015;41:81-88.

3. Kellum JA, Lameire N, Aspelin P, Barsoum RS, Burdmann EA, Goldstein SL, Herzog CA, Joannidis M, Kribben A, Levey AS, MacLeod AM, Mehta RL, Murray PT, Naicker S, Opal SM, Schaefer F, Schetz M, Uchino S. Kidney Disease: Improving Global Outcomes (KDIGO) Acute Kidney Injury Work Group. KDIGO clinical practice guideline for acute kidney injury. Kidney Int. 2012;2:1-138.

4. Pettilä V, Bellomo R. Understanding acute kidney injury in sepsis. Intensive Care Med. 2014;40:1018-1020.

5. Murugan R, Karajala-Subramanyam V, Lee M, Yende S, Kong L, Carter M, Angus DC, Kellum JA. Acute kidney injury in non-severe pneumonia is associated with an increased immune response and lower survival. Kidney Int. 2010;77:527-535.

6. Gomez H, Ince C, De Backer D, Pickkers P, Payen D, Hotchkiss J, Kellum JA. A unified theory of sepsis-induced acute kidney injury: inflammation, microcirculatory dysfunction, bioenergetics, and the tubular cell adaptation to injury. Shock. 2014;41:3-11.

This article is protected by copyright. All rights reserved. 
7. Chawla LS, Seneff MG, Nelson DR, Williams M, Levy H, Kimmel PL, Macias WL. Elevated plasma concentrations of IL-6 and elevated APACHE II score predict acute kidney injury in patients with severe sepsis. Clin J Am Soc Nephrol. 2007;2:22-30.

8. Payen D, Lukaszewicz AC, Legrand M, Gayat E, Faivre V, Megarbane B, Azoulay E, Fieux F, Charron D, Loiseau P, Busson M. A multicentre study of acute kidney injury in severe sepsis and septic shock: association with inflammatory phenotype and HLA genotype. PLoS One. 2012;7:e35838.

9. Hayashi H, Imanishi N, Ohnishi M, Tojo SJ. Sialyl Lewis X and anti-P-selectin antibody attenuate lipopolysaccharide-induced acute renal failure in rabbits. Nephron. 2001;87:352-360.

10. Cunningham PN, Dyanov HM, Park P, Wang J, Newell KA, Quigg RJ. Acute renal failure in endotoxemia is caused by TNF acting directly on TNF receptor-1 in kidney. J Immunol. 2002;168:5817-5823.

11. Cunningham PN, Wang Y, Guo R, He G, Quigg RJ. Role of Toll-like receptor 4 in endotoxin-induced acute renal failure. J Immunol. 2004;172:2629-2635.

12. Singbartl K, Bockhorn SG, Zarbock A, Schmolke M, Van Aken H. T cells modulate neutrophil-dependent acute renal failure during endotoxemia: critical role for CD28. $J$ Am Soc Nephrol. 2005;16:720-728.

13. Castoldi A, Braga TT, Correa-Costa M, Aguiar CF, Bassi ÊJ, Correa-Silva R, Elias RM, Salvador F, Moraes-Vieira PM, Cenedeze MA, Reis MA, Hiyane MI, PacheroSilva A, Goncalves GM, Saraiva Camara NO. TLR2, TLR4 and the MYD88 signaling pathway are crucial for neutrophil migration in acute kidney injury induced by sepsis. PLoS One. 2012;7:e37584.

14. Herter JM, Rossaint J, Spieker T, Zarbock A. Adhesion molecules involved in neutrophil recruitment during sepsis-induced acute kidney injury. J Innate Immun. 2014;6:597-606.

This article is protected by copyright. All rights reserved. 
15. Sideras P, Apostolou E, Stavropoulos A, Sountoulidis A, Gavriil A, Apostolidou A, Andreakos E. Activin, neutrophils, and inflammation: just coincidence? Semin Immunopathol. 2013;35:481-499.

16. Jones KL, Brauman JN, Groome NP, de Kretser DM, Phillips DJ. Activin A release into the circulation is an early event in systemic inflammation and precedes the release of follistatin. Endocrinology. 2000;141:1905-1908.

17. Jones KL, de Kretser DM, Clarke IJ, Scheerlinck JP, Phillips DJ. Characterisation of the rapid release of activin A following acute lipopolysaccharide challenge in the ewe. J Endocrinol. 2004;182:69-80.

18. Jones KL, Mansell A, Patella S, Scott BJ, Hedger MP, de Kretser DM, Phillips DJ. Activin $\mathrm{A}$ is a critical component of the inflammatory response, and its binding protein, follistatin, reduces mortality in endotoxemia. Proc Natl Acad Sci U SA. 2007; 104:16239-16244.

19. Chen Y, Wu H, Winnall WR, Loveland KL, Makanji Y, Phillips DJ, Smith JA, Hedger MP. Tumour necrosis factor- $\alpha$ stimulates human neutrophils to release preformed activin A. Immunol Cell Biol. 2011;89:889-896.

20. Wu H, Chen Y, Winnall WR, Phillips DJ, Hedger MP. Regulation of activin A release from murine bone marrow-derived neutrophil precursors by tumour necrosis factor- $\alpha$ and insulin. Cytokine. 2013;61:199-204.

21. Wu H, Chen Y, Winnall WR, Phillips DJ, Hedger MP. Acute regulation of activin A and its binding protein, follistatin, in serum and tissues following lipopolysaccharide treatment of adult male mice. Am J Physiol Regul Integr Comp Physiol. 2012;303:R665-R675.

22. Yan Q, Jingyan G, Chunhui M, Na W, Xueling C, Zhonghui L. Activin A regulates activation of mouse neutrophils by Smad3 signalling. Open Biol. 2017;7:160342.

23. Michel U, Ebert S, Phillips D, Nau R. Serum concentrations of activin and follistatin are elevated and run in parallel in patients with septicemia. Eur $J$ Endocrinol. 2003;148:559-564.

This article is protected by copyright. All rights reserved. 
24. Lee JK, Choi SM, Lee J, Park YS, Lee CH, Yim JJ, Yoo CG, Kim YW, Han SK, Lee SM. Serum activin-A as a predictive and prognostic marker in critically ill patients with sepsis. Respirology. 2016;21:891-897.

25. De Kretser DM, Bensley JG, Pettilä V, Linko R, Hedger MP, Hayward S, Allan CA, McLachlan RI, Ludlow H, Phillips DJ. Serum activin A and B levels predict outcome in patients with acute respiratory failure: a prospective cohort study. Crit Care. 2013;17:R263.

26. Stillie R, Farooq SM, Gordon JR, Stadnyk AW. The functional significance behind expressing two IL-8 receptor types on PMN. J Leukoc Biol. 2009;86:529-543.

27. Bergin DA, Reeves EP, Meleady P, Henry M, McElvaney OJ, Carroll TP, Condron C, Chotirmall SH, Clynes M, O’Neill SJ, McElvaney NG. a-1 Antitrypsin regulates human neutrophil chemotaxis induced by soluble immune complexes and IL-8. J Clin Invest. 2010;120:4236-4250.

28. Mariano F, Tetta C, Guida G, Triolo G, Camussi G. Hemofiltration reduces the serum priming activity on neutrophil chemiluminescence in septic patients. Kidney Int. 2001;60:1598-1605.

29. Linas SL, Whittenburg D, Repine JE. Role of neutrophil derived oxidants and elastase in lipopolysaccharide-mediated renal injury. Kidney Int. 1991;39:618-623.

30. Nisula S, Kaukonen KM, Vaara ST, Korhonen AM, Poukkanen M, Karlsson S, Haapio M, Inkinen O, Parviainen I, Suojaranta-Ylinen R, Laurila JJ, Tenhunen J, Reinikainen M, Ala-Kokko T, Ruokonen E, Kuitunen A, Pettilä V; FINNAKI Study Group. Incidence, risk factors and 90-day mortality of patients with acute kidney injury in Finnish intensive care units: the FINNAKI study. Intensive Care Med. 2013;39:420-428.

31. Bone RC, Balk RA, Cerra FB, Dellinger RP, Fein AM, Knaus WA, Schein RM, Sibbald WJ. Definitions for sepsis and organ failure and guidelines for the use of innovative therapies in sepsis. The ACCP/SCCM Consensus Conference Committee.

This article is protected by copyright. All rights reserved. 
American College of Chest Physicians/Society of Critical Care Medicine. Chest. 1992;101:1644-1655.

32. National Kidney Foundation: K/DOQI Clinical Practice Guidelines for Chronic Kidney Disease: Evaluation, Classification and Stratification. Am J Kidney Dis. 2002;39:2:S1S266.

33. Fisher J, Russell JA, Bentzer P, Parsons D, Secchia S, Mörgelin M, Walley KR, Boyd $\mathrm{JH}$, Linder A. Heparin-binding protein (HBP): a causative marker and potential target for heparin treatment of human sepsis-induced acute kidney injury. Shock. 2017;48:313-320.

34. Tydén J, H. Herwald, M. Hultin HM, J. Walldén J, Johansson J. Heparin-binding protein as a biomarker of acute kidney injury in critical illness. Acta Anaesthesiol Scand. 2017;61:797-803.

35. Linko R, Hedger MP, Pettilä V, Ruokonen E, Ala-Kokko T, Ludlow H, de Kretser DM. Serum activin $A$ and $B$, and follistatin in critically ill patients with influenza $A(H 1 N 1)$ infection. BMC Infect Dis. 2014;14:253.

36. Liu KD, Altmann C, Smits G, Krawczeski CD, Edelstein CL, Devarajan P, Faubel S. Serum interleukin- 6 and interleukin-8 are early biomarkers of acute kidney injury and predict prolonged mechanical ventilation in children undergoing cardiac surgery: a case-control study. Crit Care. 2009;13:R104.

37. Tapper H, Karlsson A, Mörgelin M, Flodgaard H, Herwald H. Secretion of heparinbinding protein from human neutrophils is determined by its localization in azurophilic granules and secretory vesicles. Blood. 2002;99:1785-1793.

38. Linder A, Åkesson P, Inghammar M, Treutiger CJ, Linnér A, Sundén-Cullberg J. Elevated plasma levels of heparin-binding protein in intensive care unit patients with severe sepsis and septic shock. Crit Care. 2012;16:R90.

39. Poukkanen M, Vaara ST, Pettilä V, Kaukonen KM, Korhonen AM, Hovilehto S, Inkinen O, Laru-Sompa R, Kaminski T, Reinikainen M, Lund V, Karlsson S, and the

This article is protected by copyright. All rights reserved. 
FINNAKI study group. Acute kidney injury in patients with severe sepsis in Finnish Intensive Care Units. Acta Anaesthesiol Scand. 2013;57:863-872.

Table 1. Patient characteristics and clinical outcome by acute kidney injury (AKI).

Data were available in all 182 patients and are expressed as median [IQR] or count (\%).

\begin{tabular}{|l|l|l|l|}
\hline & No AKI $(\mathrm{n}=90)$ & AKI $(\mathrm{n}=92)$ & p value \\
\hline Age, median [IQR] & $61[47.8-72]$ & $64.5[55-72]$ & 0.058 \\
\hline Male gender, $\mathrm{n}(\%)$ & $60(66.7)$ & $55(59.8)$ & 0.418 \\
\hline Co-morbidities & & & \\
\hline Hypertension, $\mathrm{n}(\%)$ & $34 / 89(38.2)$ & $53 / 91(58.2)$ & 0.012 \\
\hline Diabetes, $\mathrm{n}(\%)$ & $14 / 90(15.6)$ & $25 / 92(27.2)$ & 0.084 \\
\hline Atherosclerosis, $\mathrm{n}(\%)$ & $5 / 89(5.6)$ & $12 / 91(13.0)$ & 0.191 \\
\hline Systolic heart failure, $\mathrm{n}(\%)$ & $9 / 88(10.2)$ & $4 / 91(4.4)$ & 0.336 \\
\hline Admission type & & & \\
\hline Emergency, $\mathrm{n}(\%)$ & $89(98.9)$ & $90(97.8)$ & 1.000 \\
\hline Operative, $\mathrm{n}(\%)$ & $20 / 90(22.2)$ & $21 / 91(23.1)$ & 1.000 \\
\hline Disease severity & & & \\
\hline $\begin{array}{l}\text { SAPS II, without age and renal } \\
\text { components, median [IQR] }\end{array}$ & $24.5[19-36]$ & $26[21-35]$ & 0.618 \\
\hline Septic shock, $\mathrm{n}(\%)$ & $56(62.2)$ & $75(81.5)$ & 0.006 \\
\hline $\begin{array}{l}\text { SOFA, maximum without renal } \\
\text { points, median [IQR] }\end{array}$ & $8[5.8-10]$ & $10[7-11]$ & 0.007 \\
\hline $\begin{array}{l}\text { ICU length of stay in days, } \\
\text { median [IQR] }\end{array}$ & $4.6[2.5-7.9]$ & $4.4[2.8-8.1]$ & 0.609 \\
\hline 90-day mortality, $\mathrm{n}(\%)$ & $21(23.3)$ & $27(29.3)$ & 0.452 \\
\hline
\end{tabular}

This article is protected by copyright. All rights reserved. 
Table 2. Biomarkers according to the presence or absence of acute kidney injury (AKI).

Data are expressed as median [IQR]. ${ }^{*} p<0.05 ;{ }^{* \star} p<0.01 ;{ }^{* \star} p \leq 0.001,24 \mathrm{~h}$ vs. $0 \mathrm{~h}$.

Urine was available in 118 patients. Minimum leukocyte count and maximum CRP values for the period of 24 hours prior to admission to intensive care unit, including the time of admission, were available in 160 and 172 patients, respectively.

\begin{tabular}{|c|c|c|c|c|c|}
\hline & & All & No AKI $(n=90)$ & AKI $(n=92)$ & AKI vs. no AKI \\
\hline Activin A & Plasma 0 h & 661 [368-1287] & 469 [285-862] & 845 [554-1895] & $p<0.001$ \\
\hline & \begin{tabular}{|l|} 
Plasma 24 h \\
\end{tabular} & $\begin{array}{l}563[389- \\
1060]^{\star \star \star}\end{array}$ & 470 [301-827] & $\begin{array}{l}795[433- \\
1363]^{\star *}\end{array}$ & $\mathrm{p}<0.001$ \\
\hline & Urine $\mathbf{0 ~} \mathrm{h}$ & $7.1[0.0-41.1]$ & $4,0[0.0-33.0]$ & 9.7 [1.4-42.6] & $p=0.064$ \\
\hline IL-8 & Plasma $0 \mathrm{~h}$ & $101[30-673]$ & 50 [19-164] & 240 [60-971] & $p<0.001$ \\
\hline & Plasma 24 h & $47[20-120]^{\star \star \star}$ & $32[13-74]^{\star \star *}$ & $79[31-219]^{\star \star \star}$ & $p<0.001$ \\
\hline & Urine $\mathbf{O} \mathrm{h}$ & $23.5[6,9-95,5]$ & $9.5[2,7-28,7]$ & $\begin{array}{l}50.4[19,8- \\
145,3]\end{array}$ & $\mathrm{p}<0.001$ \\
\hline IL-6 & Plasma $0 \mathrm{~h}$ & 203 [53-947] & 109 [38-366] & 402 [73-2148] & $p=0.001$ \\
\hline & Plasma 24 h & $101[31-278]^{\star \star \star}$ & $52[0-143]^{\star \star *}$ & $182[67-696]^{\star \star \star}$ & $p<0.001$ \\
\hline & Urine $\mathbf{O} \mathrm{h}$ & $48.6[20.6-80.7]$ & $37.8[11.4-67.2]$ & $\begin{array}{l}67.7 \text { [28.7- } \\
147.9]\end{array}$ & $\mathrm{p}<0.001$ \\
\hline MPO & Plasma 0 $\mathrm{h}$ & $151[100-248]$ & 144 [88-215] & 169 [111-300] & $p=0.059$ \\
\hline & Plasma 24 h & $167[110-261]^{\star}$ & $132[103-211]$ & $207[136-323]^{\star \star}$ & $p<0.001$ \\
\hline & Urine $\mathbf{~ h ~}$ & $3.9[1.0-10.5]$ & $1.9[0.4-6.9]$ & $7.7[1.5-12.6]$ & $p<0.001$ \\
\hline B-Leukocy & tes $\min (\mathrm{E} 9 / \mathrm{I})$ & $10.3[5.5-15.6]$ & $9.2[5.4-13.5]$ & $11.4[6.1-16.1]$ & $p=0.19$ \\
\hline P-CRP ma & $\mathrm{x}(\mathrm{mg} / \mathrm{l})$ & 163 [61-259] & 122 [49-256] & 173 [102-267] & $p=0.11$ \\
\hline
\end{tabular}

This article is protected by copyright. All rights reserved. 
Figure legends

Figure 1. Study flow chart.

Figure 2. Plasma activin A, interleukin-8 (IL-8), interleukin-6 (IL-6), and myeloperoxidase (MPO) on admission to intensive care unit $(0 \mathrm{~h})$ and 24 hours thereafter (24 h) in patients without AKI (white bars), stage 1 (the lightest grey bars), stage 2 (grey bars), and stage 3 AKI (the darkest grey bars).

${ }^{*}, p<0.01$ and ${ }^{* *}, p<0.005,0 \mathrm{~h}$ vs. $24 \mathrm{~h}$ in the Mann-Whitney test with the Bonferroni corrected significance level of $p<0.0125$.

$\#, p<0.05$ and \#\#, $p<0.01$, KDIGO grade 1 vs. KDIGO grade 3 in the Kruskal-Wallis test with pairwise comparison as the post hoc test.

Figure 3. Urine activin A, interleukin-8 (IL-8), interleukin-6 (IL-6), and myeloperoxidase (MPO) on admission to intensive care unit in patients without AKI (white bars), stage 1 (the lightest grey bars), stage 2 (grey bars), and stage 3 AKI (the darkest grey bars).

\#\#, $\mathrm{p}<0.01, \mathrm{KDIGO}$ grade $1 \mathrm{vs.} \mathrm{KDIGO}$ grade 3 in the Kruskal-Wallis test with pairwise comparison as the post hoc test.

Figure S1. Time from ICU admission to the development of the first organ dysfunction.

Negative value denotes that the organ dysfunction has occurred before admission.

This article is protected by copyright. All rights reserved. 
Figure S2. Time from ICU admission to the diagnosis of AKI.

One patient, who developed AKI 13.3 hours before admission to ICU, is left out of the figure as an outlier.

Figure S3. Ln of urine MPO plotted against In of urine IL-8 $(R=0.627, p<0.001$ in Spearman's correlation test).

KDIGO 0 (white), KDIGO 1 (light grey), KDIGO 2 (dark grey) and KDIGO 3 (black).

Zero values (IL-8: 8 patients and MPO: 2 patients) are replaced with a value 0.01 for logarithmic transformation.

This article is protected by copyright. All rights reserved. 
237 adults with severe sepsis diagnosed $<24$ hours prior

to ICU admission or D0-1 of intensive care

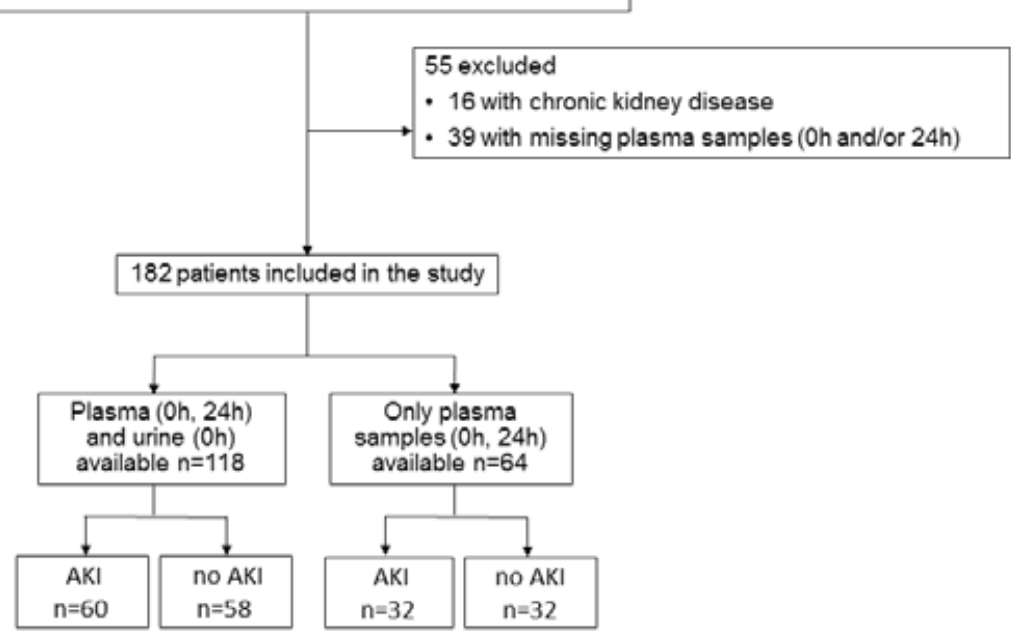

$I C U$, intensive care unit; $D O$, admission day; $D 1$, first complete calendar day; $A K I$, acute kidney injury

This article is protected by copyright. All rights reserved. 

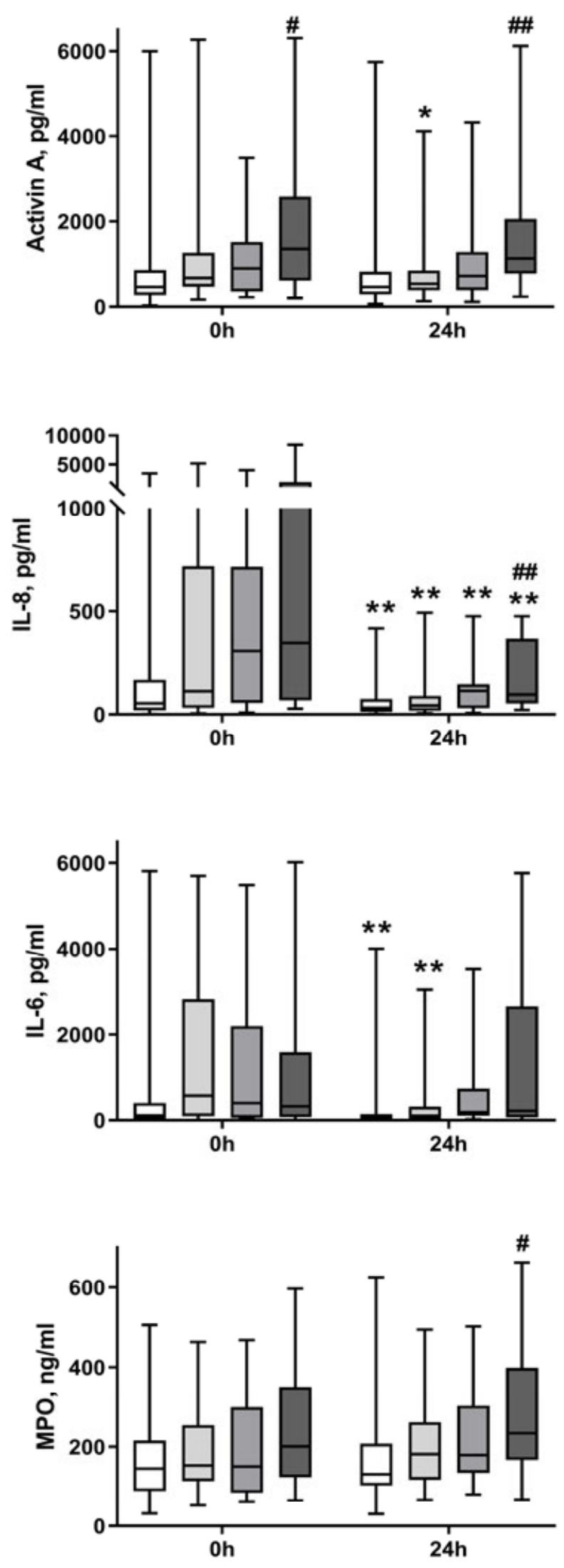

This article is protected by copyright. All rights reserved. 

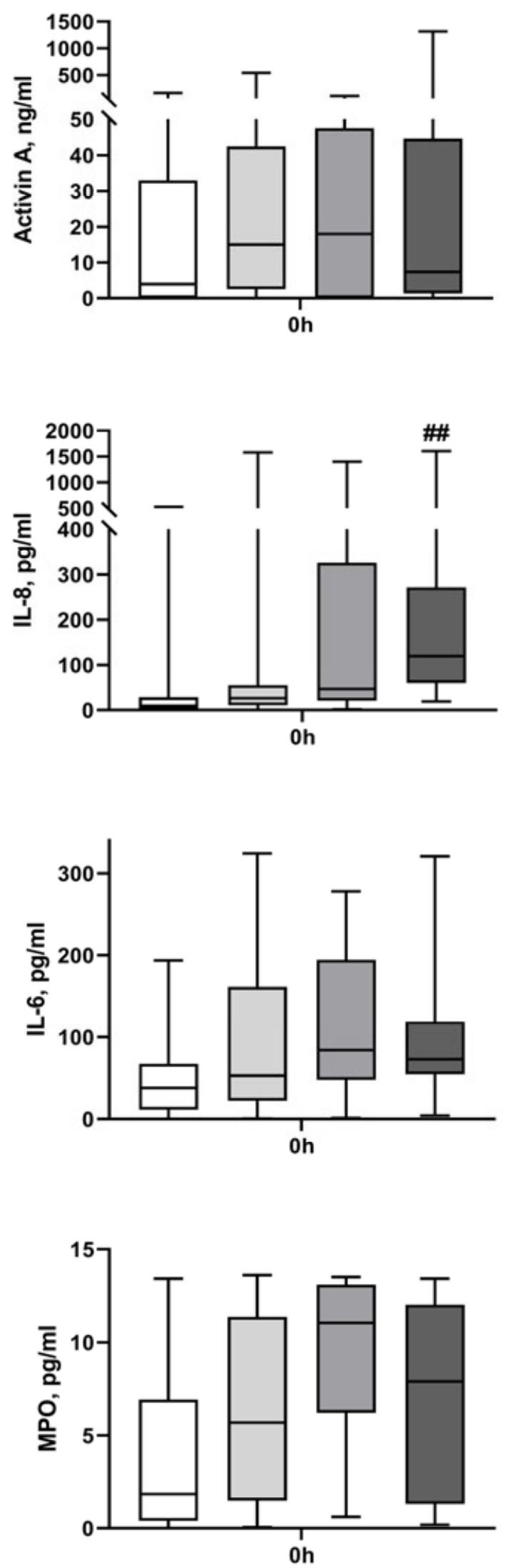

This article is protected by copyright. All rights reserved. 